\title{
Intoxicação aguda por fluorsilicato de sódio em bovinos no Estado de Santa Catarina ${ }^{1}$
}

\author{
Joelma Lucioli ${ }^{2}$, Fernando H. Furlan² ${ }^{2}$, Sara Mezaroba ${ }^{3}$, Djeison L. Raymundo ${ }^{4}$, \\ Sergio L. Bechtold ${ }^{5}$, Sandra D. Traverso ${ }^{6 "}$ e Aldo Gava ${ }^{6}$
}

\begin{abstract}
Lucioli J., Furlan F.H., Mezaroba S., Bechtold S.L., Gava A. \& Traverso S.D. 2007. [Acute sodium fluorsilicate poisoning in cattle in the state of Santa Catarina.] Intoxicação aguda por fluorsilicato de sódio em bovinos no Estado de Santa Catarina. Pesquisa Veterinária Brasileira 27(1):49-52. Laboratório de Patologia Animal, Departamento de Clínica e Patologia, Faculdade de Veterinária, UDESC, Avenida Luís de Camões 2090, Lages, SC 88520-000, Brazil.E-mail: a2sdt@cav.udesc.br

An acute poisoning with sodium fluorsilicate in six cattle is reported, as well as the experimental reproduction by oral administration of the compound to two bovines. Clinical manifestations of the natural poisoning include muscle tremors, hypersalivation, groaning and rapid death. In the experimental poisoning lateral recumbency, dyspnea, tetanic spasms and paddling was also observed. The main necropsy findings were reddening, edema and ulceration of the ruminal and abomasal mucosa. Histopathological findings were necrosis of the epithelium of the forestomachs with polymorphonuclear infiltration of the submucosal and muscular layers. Tubular renal necrosis, liver portal necrosis and necrosis of the lymphoid tissues was also noted. The sodium fluorsilicate caused clinical signs at a dose of $300 \mathrm{mg} / \mathrm{kg}$, and death from $400 \mathrm{mg} / \mathrm{kg}$ on.
\end{abstract}

INDEX TERMS: Sodium fluorsilicate poisoning, cattle, pathology.

RESUMO.- Descreve-se um surto de intoxicação aguda por fluorsilicato de sódio em seis bovinos e a reprodução experimental da intoxicação, através da administração de fluorsilicato de sódio a dois animais. $\mathrm{O}$ quadro clínico era caracterizado por tremores musculares em todo o corpo, salivação intensa, gemidos e inquietação, com morte rápida. Na intoxicação experimental foi observado também decúbito lateral, com respiração dificultosa, contração tônica e episódios de pedalagem. As le-

\footnotetext{
${ }^{1}$ Recebido em 11 de setembro de 2006.

Aceito para publicação em 2 de outubro de 2006.

2 Pós-Graduando em Medicina Veterinária, área de concentração em Patologia Veterinária, Faculdade de Veterinária, Centro de Ciências Agroveterinárias (CAV), Universidade do Estado de Santa Catarina (UDESC), Av. Luiz de Camões 2090, Caixa Postal 281, Lages, SC 88520-000.

${ }^{3}$ Graduando em Medicina Veterinária, Bolsista Próbic, Faculdade de Veterinária, CAV-UDESC, Lages, SC 88520-000.

${ }^{4}$ Pós-Graduando em Medicina Veterinária, Universidade Federal do Rio Grande do Sul, Av. Bento Gonçalves 9090, Bairro Agronomia, Porto Alegre, RS 91540-000.

${ }^{5}$ Médico Veterinário, Rua 7 de Setembro, Centro, Witmarusn, SC 89157000 .

${ }^{6}$ Laboratório de Patologia Animal, Depto Clínica e Patologia, Faculdade de Veterinária, CAV-UDESC, Lages, SC 88520-000. *Autor para correspondência: a2sdt@cav.udesc.br
}

sões macroscópicas principais foram observadas no rúmen e abomaso, consistindo em mucosa difusamente vermelha, com edema de parede e ulceração. Na histologia havia necrose acentuada de segmentos da mucosa ruminal e abomasal, associada a infiltrado de polimorfonucleares na submucosa e muscular. Além de lesões gástricas os bovinos apresentavam necrose portal hepática, degeneração e necrose tubular renal e necrose de folículos linfóides. O fluorsilicato de sódio produziu sinais clínicos com 300mg/kg e morte com $400 \mathrm{mg} / \mathrm{kg}$.

TERMOS DE INDEXAÇÃO: Intoxicação por fluorsilicato de sódio, bovinos, patologia.

\section{INTRODUÇÃO}

A intoxicação aguda por flúor é rara e segundo Osweiler (1998), o flúor na natureza é geralmente encontrado na forma de fluoretos combinados a outros elementos químicos. Os níveis tóxicos do mineral para animais não são geralmente disponíveis, fazendo-se necessário a interferência do homem, na maioria das vezes, para aumentar a ingestão de flúor acima do nível considerado crítico (Radostits et al. 2000).

Os maiores surtos de intoxicação por flúor estão relacionados à ingestão de pastos ou águas contaminadas, além de suplemento mineral com quantidades excessiva de flúor. As fábricas 
de alumínio com processo eletrolítico, de ferro ou de aço com fluxo que contêm flúor, tijolos vitrificados, cobre, vidro, esmaltados e fábricas que produzem superfosfatos a partir de fosfato de rocha são fontes potenciais de flúor. A contaminação do meio ambiente com efluentes, como ácido fluorídrico, tetrafluoreto de sílica, fluorcetamina (Radostits et al. 2000), fluorsilicato de sódio e fluoreto de sódio (Humphreys 1988), são também associados a intoxicações.

A intoxicação pode ser aguda ou crônica (Humphreys 1988). A fluorose caracteriza-se por intoxicação crônica, com lesões dentárias e ósseas. A intoxicação aguda é rara e caracteriza-se por sintomatologia gastrointestinal e sinais nervosos (Rosenberger 1975, Palmer 1993). No Brasil a intoxicação crônica a partir de pastos contaminados com poluição atmosférica, produzidas por fábricas de adubo, foi descrita em bovinos no Rio Grande do Sul (Riet-Correa et al. 1983). As intoxicações agudas foram relatadas em outros países em suínos (Bain 1953), ovinos (Georgsson \& Petursson 1972), bovinos (Padberg 1972) e cães (Holmes 1946).

O objetivo desse trabalho é relatar a intoxicação aguda por flúor em bovinos, no Estado de Santa Catarina, através da ingestão de fluorsilicato de sódio; além de caracterizar o quadro clínicopatológico da intoxicação a partir da reprodução experimental da doença.

\section{MATERIAL E MÉTODOS}

Intoxicação espontânea. Em uma propriedade rural, no município de Witmarsum, Santa Catarina, 6 de 19 bovinos morreram rapidamente após ingerirem resíduo químico de uma central de tratamento de água. Dados epidemiológicos da enfermidade, sinais clínicos e alterações de necropsia foram obtidos com o veterinário responsável. Dos seis animais que morreram, três foram necropsiados e amostras de tecidos foram coletadas, fixadas em formol a $10 \%$, processadas para exame histológico e coradas pela técnica de hematoxilina e eosina (HE). Também foi coletada uma amostra de fígado, de um bovino, para exame toxicológico.

Intoxicação experimental. Reprodução experimental foi realizada a partir do fornecimento no cocho, a dois bovinos, de fluorsilicato de sódio $\left(\mathrm{Na}_{2} \mathrm{SiF}_{6}\right)$ na dosagem de $300 \mathrm{mg} / \mathrm{kg}$ e $400 \mathrm{mg} / \mathrm{kg}$. O fluorsilicato utilizado foi o mesmo que estava na propriedade onde a intoxicação espontânea ocorreu. Os animais foram mantidos em baias de alvenaria, com água, feno e ração à vontade e acompanhados por exames clínicos. O bovino que morreu por eutanásia foi necropsiado e amostras de vísceras foram coletadas para exame histológico e toxicológico.

\section{RESULTADOS \\ Intoxicação espontânea}

Em uma propriedade rural no município de Witmarsum, SC, seis de dezenove bovinos, morreram após ingerirem uma substância de cor branca e sem cheiro, que foi posteriormente identificada como fluorsilicato de sódio. Este produto foi deixado ao ar livre em uma propriedade vizinha de uma estação de tratamento de água, onde bovinos tinham livre acesso. Os animais intoxicados apresentavam tremores musculares em todo o corpo, salivação intensa, gemidos, inquietação, levantando e deitando com freqüência, morrendo rapidamente após o início dos sinais clínicos.

\section{Intoxicação experimental}

O bovino que ingeriu 300 $\mathrm{mg} / \mathrm{kg}$ (Bov.1) de fluorsilicato de sódio apresentou, 14 horas após a ingestão, salivação intensa, tremores musculares leves, principalmente na coxa; mudança freqüiente de posição e olhar constante para o flanco. No dia seguinte o quadro evolui para diarréia e ingestão freqüiente de água. Quarenta e oito horas após a ingestão o animal voltou a se alimentar, persistindo a diarréia por 5 dias seguida de recuperação completa. $O$ animal que ingeriu $400 \mathrm{mg} / \mathrm{kg}$ (Bov.2) apresentou alterações semelhantes ao Bovino 1 , mas com evolução mais rápida e de maior intensidade dos sinais clínicos. Duas horas após a ingestão o animal coiceava o ar e o abdômen, rangia os dentes, salivava, tinha tremores musculares e alternava a posição em decúbito lateral e external. Vinte sete horas após a ingestão o animal ficou em decúbito lateral, com respiração dificultosa, contração tônica e episódios de pedalagem, seguido de coma, sendo eutanasiado duas horas após o decúbito.

Durante as necropsias dos casos espontâneo e experimental, sentia-se um odor forte que lembrava derivado de petróleo. No rumem, retículo e omaso observavam-se múltiplas áreas de coloração vermelha na mucosa, associadas às áreas de ulceração, edema e desprendimento da mucosa (Fig.1). A mucosa do abomaso tinha coloração vermelha difusa, de aspecto edematoso e com erosões multifocais.

A análise histológica das amostras revelou necrose acentuada de segmentos da mucosa ruminal e abomasal e infiltrado polimorfonuclear variando de moderado a acentuado na mucosa, submucosa e muscular (Fig.2), associados ou não a hemorragia. A infiltração de neutrófilos era mais acentuada nas regiões perivasculares. Trombos de fibrina e polimorfonucleares foram vistos nos vasos da submucosa. A necrose da mucosa ruminal às vezes era associada a desprendimento do epitélio e, no caso experimental, era acompanhada de edema acentuado de submucosa. Além das lesões gástricas os bovinos apresentavam lesões no fígado, rim e tecido linfóide, caracterizadas por necrose hepática periportal (Fig.3), sendo mais acentuada nos casos espontâneos, associada a infiltrado moderado difuso de neutrófilos nos sinusóides. O epitélio tubular renal tinha

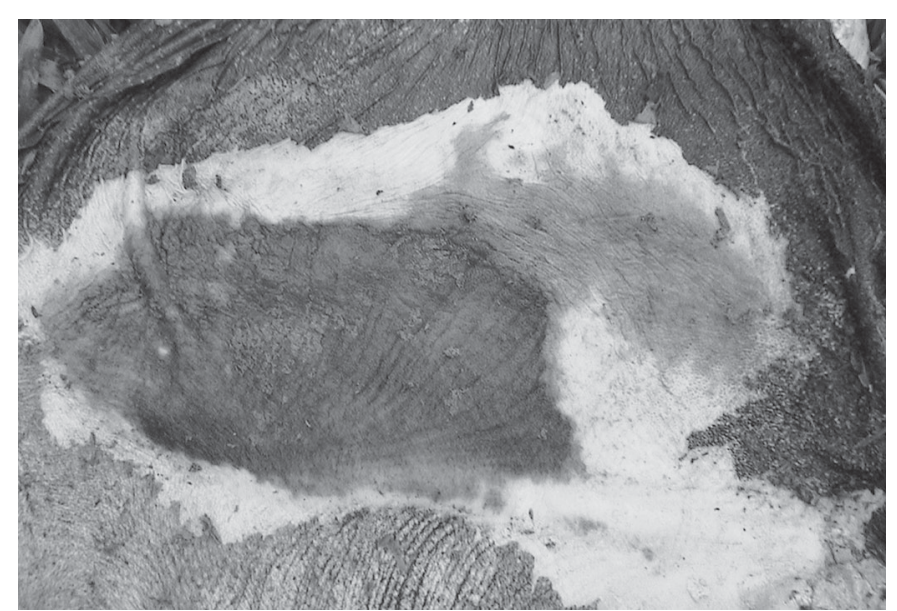

Fig.1. Áreas avermelhadas na mucosa do rúmen com desprendimento da capa queratinizada, na intoxicação espontânea de bovino por fluorsilicato de sódio. 


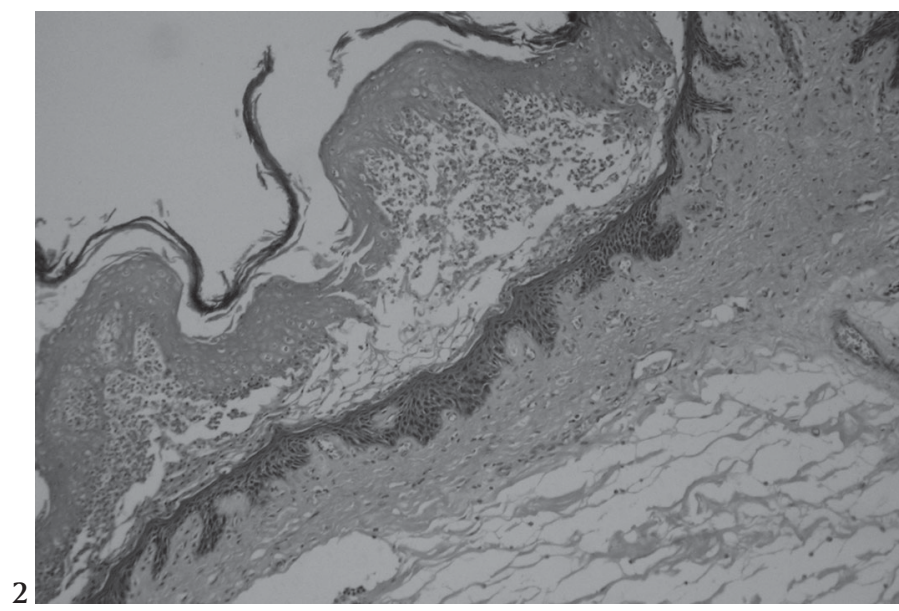

Fig.2. Necrose do epitélio de revestimento do rumem acompanhado de infiltrado polimorfonuclear, desprendimento da camada epitelial e edema de submucosa, na intoxicação experimental por fluorsilicato de sódio em bovino. HE, obj.20.

Fig.3. Necrose de hepatócitos com distribuição perilobular, na intoxicação espontânea por fluorsilicato de sódio em bovino. HE, obj.20.

Fig.4. Necrose em folículo linfóide, na intoxicação espontânea por fluorsilicato de sódio em bovino. HE, obj.20.

citoplasma de aspecto finamente granular e necrose de grupo de túbulos; no baço e linfonodos observou-se necrose moderada de folículos linfóides (Fig.4).

Os níveis de flúor no fígado constatados no exame toxicológico foram de 7,75ppm F/g para o animal da intoxicação espontânea e de 1,14ppm F/g para o animal da intoxicação experimental.

\section{DISCUSSÃO E CONCLUSÃO}

A doença observada nos bovinos em Santa Catarina está relacionada à ingestão espontânea de fluorsilicato de sódio. O diagnóstico foi efetuado através de dados epidemiológicos, sinais clínicos, lesões macro e microscópicas e comprovação através da reprodução do quadro clínico-patológico em dois bovinos, que ingeriram, de forma voluntária e rápida, o produto encontrado no local da intoxicação espontânea.

A intoxicação aguda por flúor em bovinos, geralmente é acidental e favorecida pela ausência de caracteres organolépticos muito acentuados [cor branca, sabor e aroma nulos] (Fabre \& Truhaut 1971). Estas características provavelmente foram fundamentais para a ingestão voluntária de fluorsilicato de sódio após este ter sido depositado inadvertidamente no local onde ocorreu a intoxicação.

A quantidade de fluorsilicato de sódio necessária para produzir a morte em bovinos é de $400 \mathrm{mg} / \mathrm{kg}$ a $2 \mathrm{~g} / \mathrm{kg}$ (Radostits 2000). No presente trabalho a ingestão deste produto na dose de $300 \mathrm{mg} / \mathrm{kg}$ produziu em um bovino, fortes sinais clínicos com recuperação posterior e quantidades de $400 \mathrm{mg} / \mathrm{kg}$ em um segundo bovino produziram fortes alterações clinicas; o animal morreu quando se encontrava em estágio terminal da doença. $A$
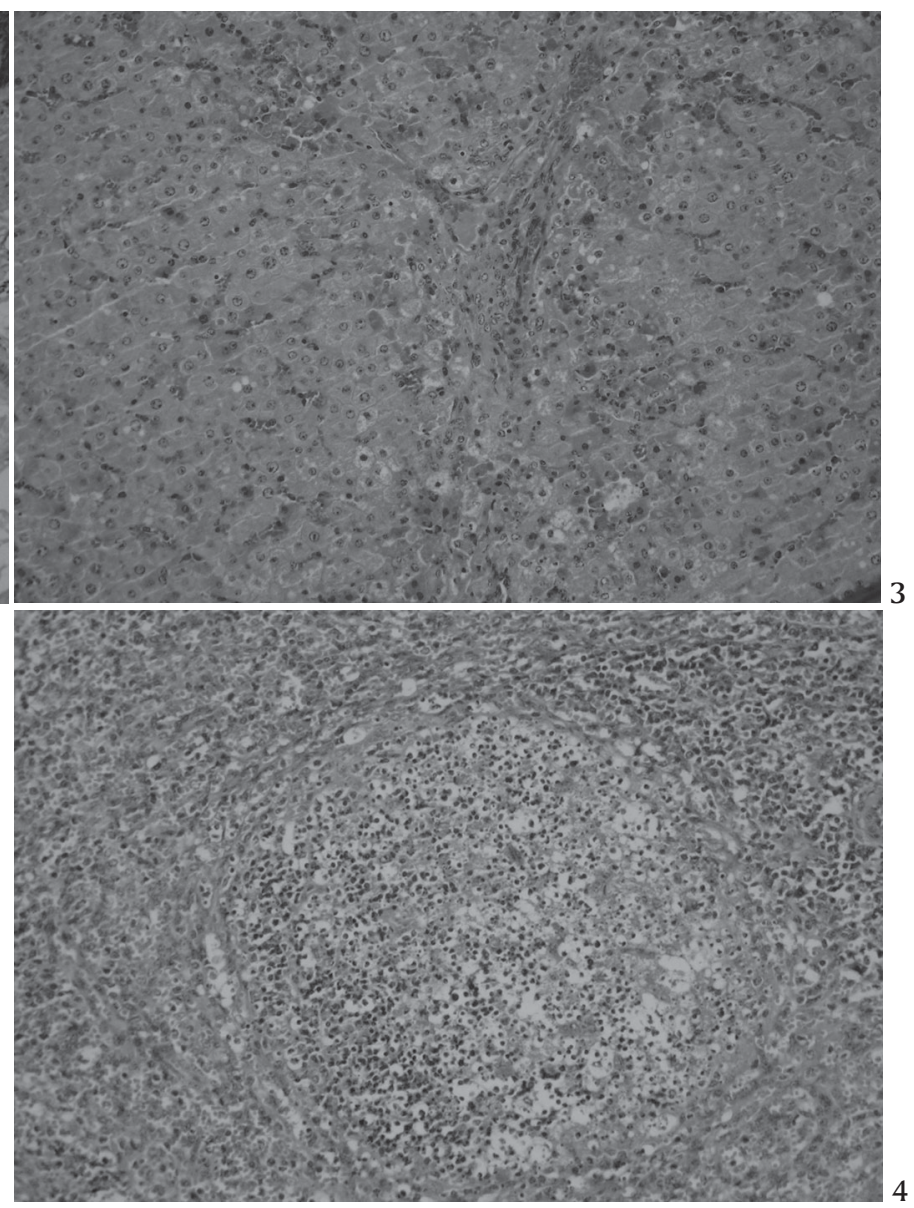

dosagem de flúor analisada no fígado de dois animais foi de 7,75ppm para o bovino que morreu da doença espontânea, e $1,14 \mathrm{ppm}$ para o bovino que morreu da intoxicação experimental. Por estes valores, pode-se dizer que os bovinos que morreram pela intoxicação espontânea, ingeriram quantidades altas de fluorsilicato de sódio, demonstrando que este produto é bem aceito pelos bovinos.

As ingestões espontânea e experimental por fluorsilicato de sódio em bovinos produziram sinais clínicos e lesões características de distúrbios digestivos. Este quadro clínico-patológico foi semelhante ao descrito na intoxicação aguda por flúor. Animais que ingerem quantidades altas deste elemento químico em um curto período de tempo apresentam polidipsia, sialorréia, movimentos constantes de mastigação, ranger de dente, dor abdominal e diarréia. Não havendo regressão dos sinais clínicos o quadro evolui para excitabilidade, contrações musculares, decúbito lateral, diminuição da freqüência cardíaca e morte (Rosenberger 1975). As alterações no ritmo cardíaco, os tremores musculares e os sinais neurológicos de contração tônica devem-se a fixação do cálcio sérico para formar no plasma fluoreto de cálcio, fisiologicamente inativo (Rosenberger 1975, Radostits et al. 2000). A irritação gastroentérica é decorrente da formação de ácido fluorídrico no ambiente ácido dos estômagos (Radostits et al. 2000), e possivelmente este seja o responsável pelo forte odor exalado durante a necropsia, podendo auxiliar na confirmação do diagnóstico. 
Intoxicação aguda com flúor inorgânico interrompe inúmeros sistemas fisiológicos. Como um elemento eletronegativo, o flúor se liga fortemente aos cátions essenciais para homeostasia, produzindo hipocalcemia grave e inibição da coagulação normal do sangue. Como um metabólito tóxico, ele estimula algumas enzimas como a adenil ciclase e inibe outras como a Na ${ }^{(+)} / \mathrm{K}^{(+)}$-ATPase e enzimas do catabolismo dos carboidratos (Mclvor 1990). A morte resulta da hipercalemia associada às alterações na condutibilidade cardíaca, bem como pela hipocalcemia (Beasley 1999).

O flúor é passivamente absorvido no intestino, sendo aproximadamente metade deste excretado na urina e o restante armazenado no tecido ósseo (Beasley 1999). A necrose de rúmen e abomaso observadas são descritas nas intoxicações agudas por flúor (Barker et al. 1993). A lesão de abomaso é secundária a atividade ácida do flúor e a lesão renal deve-se principalmente por que os túbulos proximais são mais susceptíveis a agentes tóxicos, devido sua alta atividade metabólica e a exposição em grande quantidade a agentes nocivos pelo ultrafiltrado glomerular, que serão reabsorvidos no processo de formação da urina (Maxie 1993). A necrose tubular renal secundária a intoxicações aguda por flúor foram também descritas por Georgsson \& Petursson (1972). A necrose portal de hepatócitos e de folículos linfóides não foram relatadas nas outras intoxicações agudas por flúor, mas o N-hidroxil2-acetilaminofluoreno é relatado como causa de necrose portal de hepatócitos (Kelly 1993).

Em medicina veterinária a intoxicação aguda por flúor em bovinos é rara. As alterações clínicas e as lesões macro e microscópicas são semelhantes àquelas observadas na intoxicação por algumas das plantas de ação sobre o tubo digestivo. $O$ diagnóstico diferencial deve ser feito da intoxicação por Baccharis coridifolia (Tokarnia \& Döbereiner 1975, Varaschin et al. 1998,); Baccharis megapotamica var. megapotamica e var. weirii (Tokarnia et al. 1992) e Bacharidastrum triplinervium (Langohr et al. 2005).

Agradecimentos.- À Dra. Marília Afonso Rabelo Buzalaf, Departamento de Ciências Biológicas, Universidade de São Paulo, pelas análises e dosagem de flúor realizadas.

\section{REFERÊNCIAS}

Bain L.R. 1953. Postcastration hemorrhage of pigs following worming with sodium fluoride. Vet. Med. 48:124.
Barker I.K., Van Dreumel A.A. \& Palmer N. 1993 The alimentary system, p.1-317. In: Jubb K.V.F, Kennedy P.C. \& Palmer N. (ed.), Pathology of Domestic Animals. Vol.1. $4^{\text {th }}$ ed. Academic Inc., San Diego.

Beasley E.V. 1999. Veterinary Toxicology. International Information Service, Ithaca, New York.

Fabre R. \& Truhaut R. 1971. Toxicologia. Fundação Caloust Gulbenkian, Lisboa. 887p.

Georgsson G. \& Petursson G., 1972. Fluorosis of sheep caused by the Hekla eruption in 1970. Fluoride 5:58-66.

Holmes J.W.H. 1946. Toxicology. Vet Rec. 32(56):358-360.

Humphreys D.J. 1988. Veterinary Toxicology. $3^{\text {rd }}$ ed. Baillièr and Tindall, London. 356p.

Kelly W.R. 1993. The liver and biliary system, p.319-406. In: Jubb K.V.F, Kennedy P.C. \& Palmer N. (ed.), Pathology of Domestic Animals. Vol.1. 4th ed. Academic Inc., San Diego.

Langohr I.M., Gava A. \& Barros C.S.L. 2005. Intoxicação por Baccharidastrum triplinervium (Asteraceae) em bovinos. Pesq. Vet. Bras. 25(4):235-238.

Maxie M.G. 1993. The urinary system, p.447-538. In: Jubb K.V.F., Kennedy P.C. \& Palmer N. (ed.), Pathology of Domestic Animals. Vol.1. 4th ed. Academic Inc., San Diego.

McIvor M.E. 1990. Acute fluoride toxicity: pathophysiology and management. Drug Saf. 5(2):79-85.

Osweiler G.D. 1998. Toxicologia Veterinária. Editora Artes Médicas, Porto Alegre, RS. 526p.

Padberg, W. 1972. Akute Fluorvergiftung in einem Rindviehbestand. Tierärztl. Umschau 27:428-430.

Palmer N. 1993. Bone and joints, p.1-181. In: Jubb K.V.F., Kennedy P.C. \& Palmer N. (ed.), Pathology of Domestic Animals. Vol.1. 4th ed. Academic Inc., San Diego.

Radostits O.M., Gay C.C., Blood D.C. \& Hinchcliff K.W. 2000. Veterinary Medicine. 9th ed. W.B. Saunders, New York. 1977p.

Riet-Correa F., Oliveira J.A., Méndez M.C. \& Schild A.L. 1983. Poluição industrial como causa de intoxicação por flúor em bovinos no município do Rio Grande, RS. Pesq. Vet. Bras. 3(4):107-114.

Rosenberger G. 1975. Malattie del Bovino. Editora Essegive, Piancenza. 1390 p.

Tokarnia C.H. \& Döbereiner J. 1975. Intoxicação experimental em bovinos por "mio-mio", Baccharis coridifolia. Pesq. Agropec. Bras., Sér.Vet.10:7997.

Tokarnia C.H., Peixoto P.V., Gava A. \& Barros C.S.L. 1992. Intoxicação experimental por Baccharis megapotamica var. megapotamica e var. weirii (Compositae) em bovinos. Pesq. Vet. Bras. 12(1/2):19-31.

Varaschin M.S., Barros C.S.L. \& Jarvis B.B. 1998. Intoxicação experimental por Baccharis coridifolia (Compositae) em bovinos. Pesq. Vet. Bras. 18(2):69-74. 